
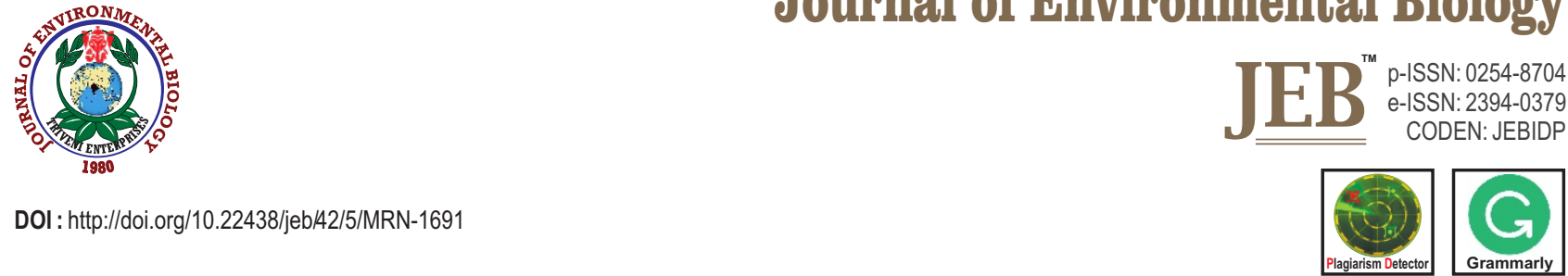

\title{
Gamma rays induced morphological, flowering and palynological modifications in horse gram (Macrotyloma uniflorum)
}

\author{
S. Priyanka ${ }^{1}$, R. Sudhagar ${ }^{2 *}$, C. Vanniarajan ${ }^{3}$, K. Ganesamurthy ${ }^{4}$ and J. Souframanien ${ }^{5}$ \\ ${ }^{1}$ Centre for Plant Breeding and Genetics, Tamil Nadu Agricultural University, Coimbatore - 641003 , India \\ ${ }^{2}$ Sugarcane Research Station, Melalathur, Tamil Nadu Agricultural University, Vellore - 635 806, India \\ ${ }^{3}$ Department of Plant Breeding and Genetics, Agricultural College and Research Institute, Tamil Nadu Agricultural University, Madurai - 625 104, India \\ ${ }^{4}$ Department of Rice, CPBG, Tamil Nadu Agricultural University, Coimbatore - 641 003, India \\ ${ }^{5}$ Nuclear Agriculture and Biotechnology Division (NA\&BTD), BARC, Mumbai - 400 085, India
}

*Corresponding Author Email : sudhagar.r@tnau.ac.in

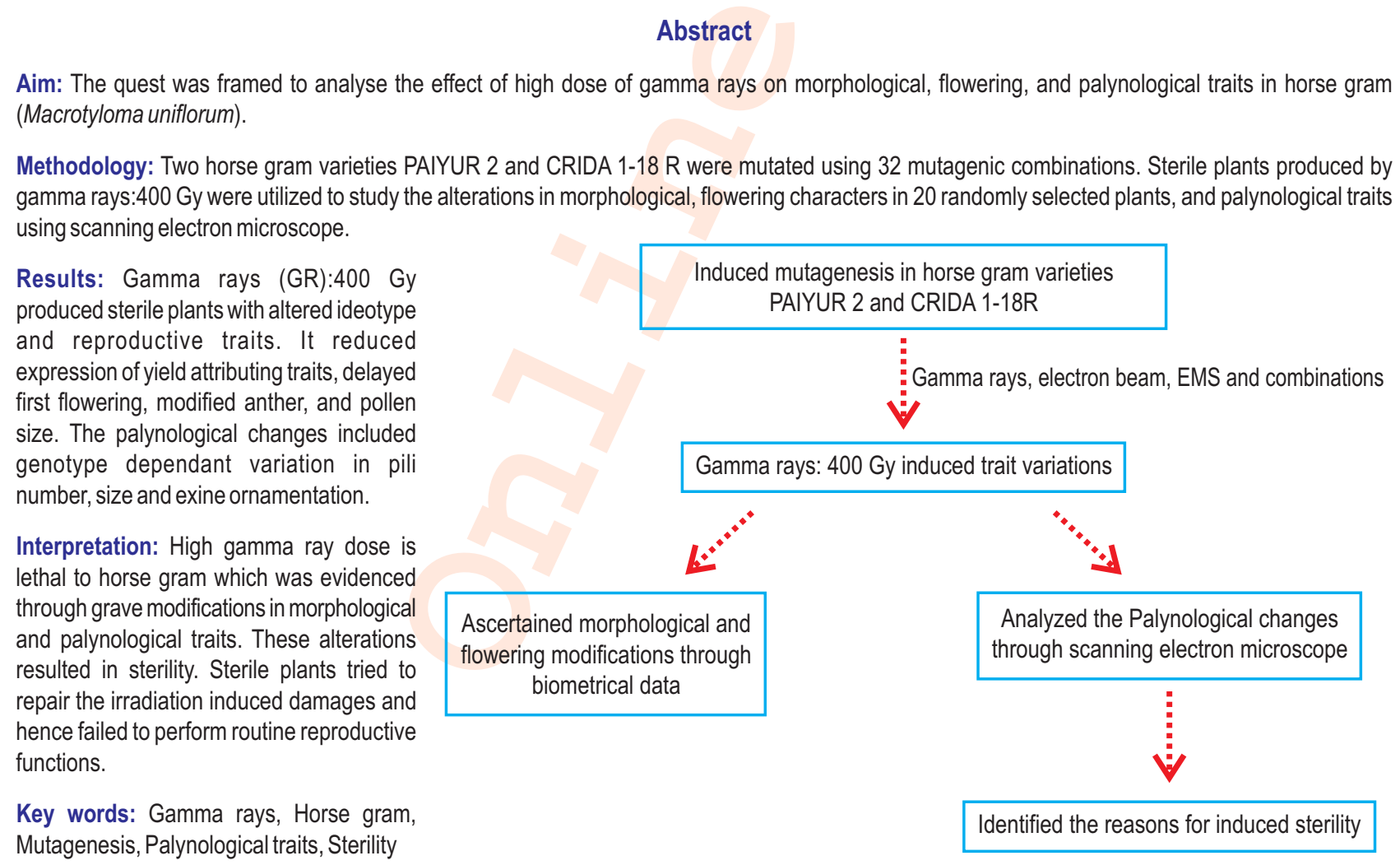

How to cite : Priyanka, S., R. Sudhagar, C. Vanniarajan, K. Ganesamurthy and J. Souframanien: Gamma rays induced morphological, flowering and palynological modifications in horse gram (Macrotyloma uniflorum). J. Environ. Biol., 42, 1363-1369 (2021). 


\section{Introduction}

World's food demand is catered by only three major cereal crops viz. rice, wheat and maize despite great plant diversity (Cheng et al., 2017). This narrow dependency poses threat to food production (Khoury et al., 2014). India is not an exception. To sustain food and nutritional security, diversification of rural cropping pattern is important (Mabhaudhi et al., 2017). The gradual yield loss in these major cereal crops and emerging stresses also necessitate diversification (Chivenge et al., 2015). The cultivation pattern of traditional Indian rural agriculture comprises of many underutilized legume crops. Exploitation of such underutilized but potential legumes is important under Indian dry land agriculture (Bhartiya et al., 2015) as rainfed farming accounts for $67 \%$ of total cultivable land in the country, which contribute to $44 \%$ of food grain production (CRIDA, 1997).

Horse gram (Macrotyloma uniflorum (Lam.) Verdc) is an underutilized legume crop. It is grown in 3.26 lakh ha (Fuller and Murphy, 2018) during Rabi season under dry and marginal land conditions by resource poor farmers in India. It has emerged as a potential commercial crop owing to its inherent ability for drought tolerance (Sharma et al., 2015), suitability for inter and mixed cropping (Krishna, 2010) and diversified uses e.g. as dal for a subsidiary source of protein (Kadam et al., 1985), nutrient loaded (Prasad and Singh, 2015) fodder for livestock and green manuring to add fertility status of the soil (Bhardwaj et al., 2013).

The area, production and productivity of horse gram are declining (Aditya et al., 2019). This decline is due to horse gram (i) is sown after northeast monsoon and largely depends on residual moisture, (ii) has fairly long duration (90-120 days), (iii) produce flowers till harvest because of indeterminate growth habit, and (iv) experience terminal drought.

Evolution of horse gram genotypes with short to medium duration and determinate growth habit could sustain the yield. Application of classical hybridization techniques in horse gram is limited due to small sized flowers and significant flower dropping. Induced mutagenesis offers scope for inducing variability in horse gram (Priyanka et al., 2019). Mutation induced alterations in plant types, fertility status and seed yield have been reported in many plants including pulses (Koti et al., 2004). Earlier Savaskan (2002) and Singh and Singh (2001) reported induction of pollen sterility at higher mutagenic doses. An insight into the mutation induced variations in pollen function provides knowledge for linking these changes with plant reproductive performance. The alterations in reproductive biology of plants can be efficiently studied using scanning electron microscope (Durate-Silva et al., 2010; Rick, 1942). reported significant variations in pollen shape and size under irradiated treatments. Sari-Gorla et al. (1996) reported that the occurrence of mutations during or immediately after the first pollen mitosis had resulted in formation of nonfunctional pollen grains. Koti et al. (2004) reported varied reproductive efficiency in UV-irradiated population of soybean. Therefore, in the present study, attempts were made to understand the gamma rays-induced morphological and flowering modifications as well as alterations in the pollen and anther morphology of horse gram using SEM.

\section{Materials and Methods}

Healthy, well filled, and genetically pure uniform sized seeds of two popular and well adapted horse gram varieties "PAIYUR 2" and "CRIDA 1-18 R" were subjected to mutagenesis with the following combinations. GR: 100 to $400 \mathrm{~Gy}$; EB: 100 to 400 Gy; G100 Gy+EB 100 Gy; G 200 Gy+EB 200 Gy, G300 Gy+EB 300 Gy; G400 Gy+EB 400 Gy; GR+EMS: 100Gy+0.3\% EMS, $200 \mathrm{~Gy}+0.3 \%$ EMS, $300 \mathrm{~Gy}+0.3 \% \mathrm{EMS}$ and $400 \mathrm{~Gy}+0.3 \%$ EMS and two controls. For combination treatment of GR and EB, the seeds were first irradiated with GR followed by GR at designated doses. For GR and EMS combination treatment, the seeds were first irradiated with GR then chemically mutagenized with EMS. The EMS concentration of $0.3 \%$ was fixed based on the findings of Bolbhat et al. (2012). A total of 500 seeds were mutagenized per treatment. Gamma rays and Electron Beam (EB) irradiations treatments were performed at Bhabha Atomic Research Centre, Mumbai. For EMS (Sigma, USA) treatment, the presoaked seeds ( 6 hours) were immersed in EMS solution prepared in sodium phosphate buffer ( $\mathrm{pH}$ of 7.0$)$ for $5 \mathrm{hrs}$ with intermittent shaking. The volume of mutagenic solution was maintained ten times proportion to that of seed volume. Treated seeds were thoroughly washed in running tap water for half an hour to eliminate the residual effect of mutagen. Excess moisture in the seed coat was removed with folds of blotting paper.

Mutagen treated seeds along with control were sown immediately at $30 \times 15 \mathrm{~cm}$ spacing with $4 \mathrm{~m}$ row length in the research blocks attached to the Department of Pulses, Centre for Plant Breeding and Genetics, TNAU, Coimbatore, Tamil Nadu during Rabi season 2017. All the critical cultivation practices were adopted in toto including need-based irrigations. Since GR: 400 Gy, caused drastic effect on flowering behavior and floral structures, data were recorded critically from such mutagenic treatment and compared with 20 randomly selected plants in controls for morphological, flowering and palynological investigations. While, for palynological study, the individual complete sterile plants from GR: 400 Gy were utilized for SEM studies.

Plant height was measured from ground level to the tip of the main axis at maturity and expressed in centimeter. The leaf area was calculated by multiplying the length and breadth of the widest region of third fully opened leaf in the main stem at peak flowering (Kanagaraj and Satish, 2017). Same third leaf was utilized to measure chlorophyll fluorescence using chlorophyll fluorometer OS1P(OPTI-SCIENCES) at bright sun shine hours. Total number of days taken from the date of sowing to production of first flower was documented as days to first flowering. The total number of flowers in all clusters was counted at peak flowering, and the average was calculated. The days taken from first flowering to cessation of pod formation in the main stem was calculated as economic flowering duration. Total number of primary branches on main stem was counted at prematurity stage 
as per Mahajan et al. (2007). Pollen grains from freshly dehisced anthers were stained with $1 \%$ potassium iodide solution, and examined under light microscope. The ratio between total number of well stained pollens and total pollen grains was calculated as pollen fertility percentage. Three microscopic plates of pollen were considered for each inflorescence and mean values were estimated. The percentage of well filled seeds was worked out for each plant at harvest and the mean seed fertility was calculated.

For SEM analysis, the anther samples were fixed in different concentrations of ethanol ( $30 \%$ to $90 \%$ ) and dehydrated. The time of fixation in each concentration was two minutes. The organic solvent was replaced with liquid carbon-di-oxide by critical point drying. The samples were coated with low-vacuum sputter coating by EMITECH (SC7620) super cool sputter coater, and mounted rigidly on a $12 \mathrm{~mm}$ diameter specimen stub using double sided adhesive carbon conducting tape. The instrument FEI QUANTA 250 was used to characterize the specimens. Pollen size was measured in polar $(P)$ and equatorial $(E)$ axis and pollen shape index (P/E) was calculated. The data were statistically analyzed by SPSS software (Version 10.0).

\section{Results and Discussion}

Two horse gram varieties were subjected to mutagenesis by applying single doses of gamma rays, EB and combinations of gamma rays with EB and EMS in order to induce variability for agro-economic traits. Both EB and GR at 400 Gy modified the plant ideotype. However, the treatment GR: 400 Gy produced remarkable and drastic changes in plant height, number of branches, leaf area, days to first flowering, economic flowering duration, number of flowers per cluster, and palynological traits. It also produced complete sterile plants in both varieties.

Gamma rays reduced plant height to a greater extent in sterile plants in both varieties (Fig. 1a). The reduction percent was 26 and 19.7 in PAIYUR 2 and CRIDA 1-18 R, respectively. Kumar and Srivastava (2011) reported reduction in plant height under irradiated condition. This is due to alterations in the meristematic cell division followed by hormonal imbalance and changes in the functionality of important metabolic enzymes (Kumar and Dwivedi, 2014). The decline in number of branches was pronounced in CRIDA 1-18 R variety (Fig. 1b). Sterile plants possessed light green coloured leaves with less leaf area. The leaf area of sterile plants of PAIYUR 2 and CRIDA 1-18 R were 22.55 and $19.42 \mathrm{~cm}^{2}$, respectively (Fig. 1c), which differed significantly compared to their respective parents. The light coloured leaves produced abridged chlorophyll a/b ratio (Fig. 1d) due to mutagenic stress. Parida and Das (2005) and Gicquel et al. (2011) reported altered photosynthesis and down regulation of chloroplast gene. Stress induced changes in major metabolic pathways including photosynthesis have been reported in horse gram (Desingh and Kanagaraj, 2007). Gamma rays irradiation delayed flowering for 5 and 4 days in PAIYUR 2 and CRIDA 1-18 $R$, respectively (Fig. 1e), and dwindled the economic flowering duration in both varieties (Fig. 1f). It was more pronounced in the cultivar PAIYUR 2. Significant reduction was observed in average number of flowers per cluster in sterile plants (Table 1) and it was $51.56 \%$ and $48.46 \%$ in PAIYUR 2 and CRIDA 1-18 R, respectively.

Horse gram has a typical papilionaceous petal orientation under normal growing conditions. However, irradiation in this study produced small sized floral buds with distorted and twisted petal orientation. The twisted petals were dark green and anthers in such flowers were fully dehisced without having fertile pollen. In contrast, the fertile flowers possessed light yellowish petals and the fertility percentage were 93.48 and 90.21 in control treatments of PAIYUR 2 and CRIDA 1-18 R, respectively (Table 1). Under high dose of GR irradiation (400 Gy), the plants divert more photosynthates and energy for repairing the irradiation induced damages that result in reduced flower size, number, and pollen count (Kakani et al., 2003). Kumar and Srivastava (2011) and and Nurmansyah et al. (2017) reported the production of smaller sized flowers with few tiny pollen grains, altered pollen morphology and germination percentage under irradiated condition. The negative effect of GR on pollen fertility is due to the collective effects of different meiotic aberrations and disturbances in normal karyokinensis and/or cytokinensis. Priyanka et al. (2020) reported a reduction in pollen fertility in $\mathrm{M}_{1}$ generation of horse gram treated with gamma rays and EMS.

The alterations in reproductive biology of plants can be efficiently studied using scanning electron microscope. An insight into the mutation induced variations in pollen function will provide knowledge for linking these changes with plant reproductive performance. It was evident that the gamma irradiation had caused significant changes in the anther and pollen morphology and the alteration was genotype dependent. Gamma rays treatment reduced anther length (Table 1). The average anther length in sterile plants of PAIYUR 2 was $306.85 \mu \mathrm{M}$, while it was $279.4 \mu \mathrm{M}$ in CRIDA 1-18 R. The anther width was increased (340 $\mu \mathrm{M})$ in PAIYUR 2 but reduced in CRIDA 1-18 R. Plants with reduced anther size consequently produced small sized pollens (both in polar and equatorial axis) and changed pollen shape index (P/E). The average P/E index of sterile plants were 0.76 and 0.86 in PAIYUR 2 and CRIDA 1-18 R, respectively, while their respective controls possessed 0.80 and 0.93 (Table 1) that caused condensation in anther wall fibre matrix (Fig. 2a, 3a).

In the variety PAIUYR 2, irradiation produced shrunken pollen, crowded pili, and pili length variation (Fig. 2 b-d) which might have caused a blockade in pollen germination. The protruding pili are important for precise pollen flight and pollen tube development (Mackenzie et al., 2014). Pili of exine origin act as an exit pathway for germinating pollen tube and helps in recognition of protein signals that initiate the development of a pollen tube. The presence of crowded apertures in sterile plants is the indication of physiological pollen damages. Further, it is hypothesid that irradiated plants thrive to repair the pollen damages by increasing the synthesis of exine borne components like sporopollenin rather than performing reproductive functions. Sporopollenin imparts resilience to pollens under stress (Brooks and Shaw, 1978). Kumar and Priyanka (2006) reported gamma 

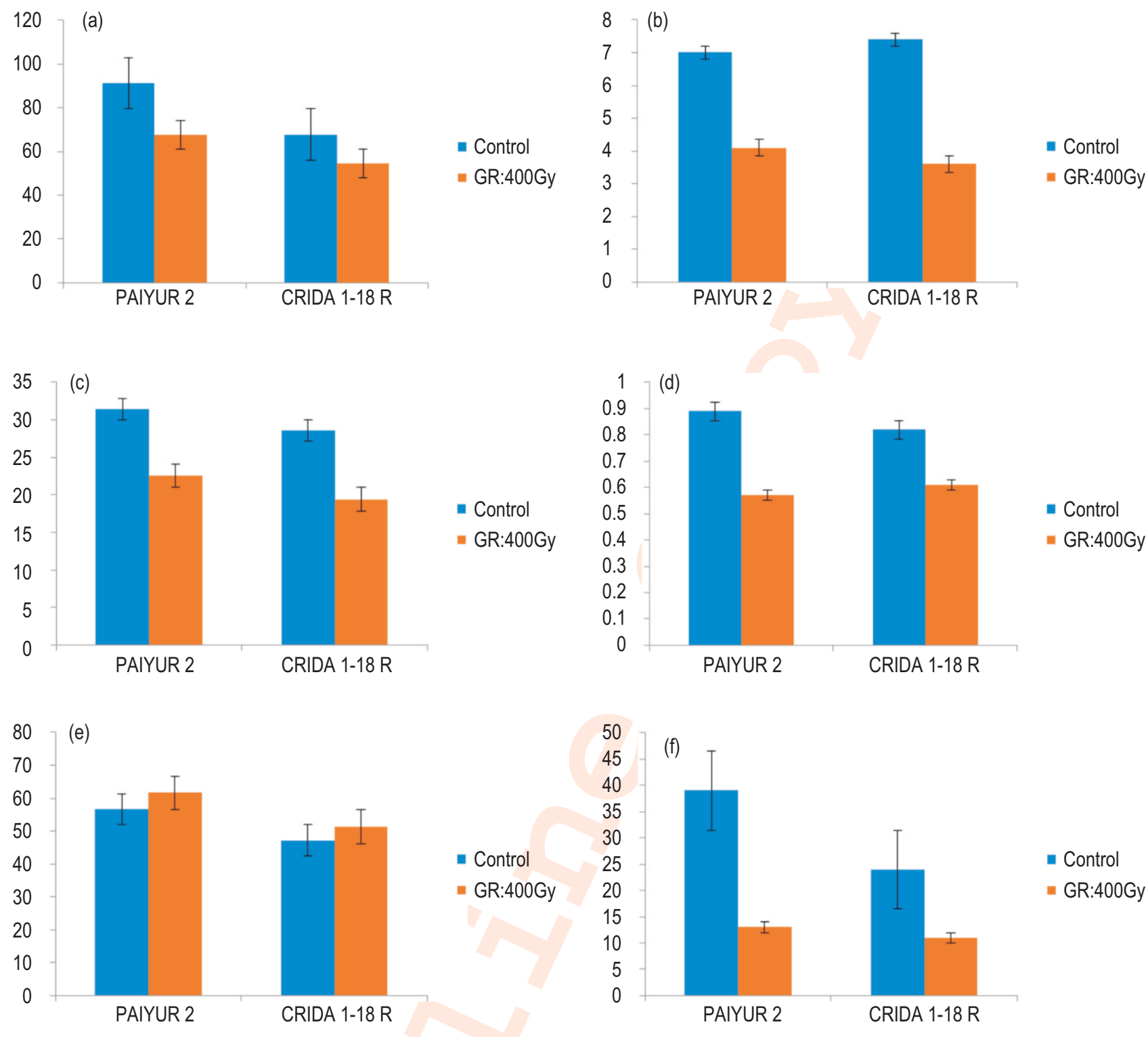

Fig. 1 (a-f) : Effect of Gamma rays radiation on (a) plant height; (b) number of primary branches in main stem; (c) leaf area (cm²); (d) chlorophyll (a/b) ratio; (e) days to first flowering and (f) economic flowering duration in horse gram.
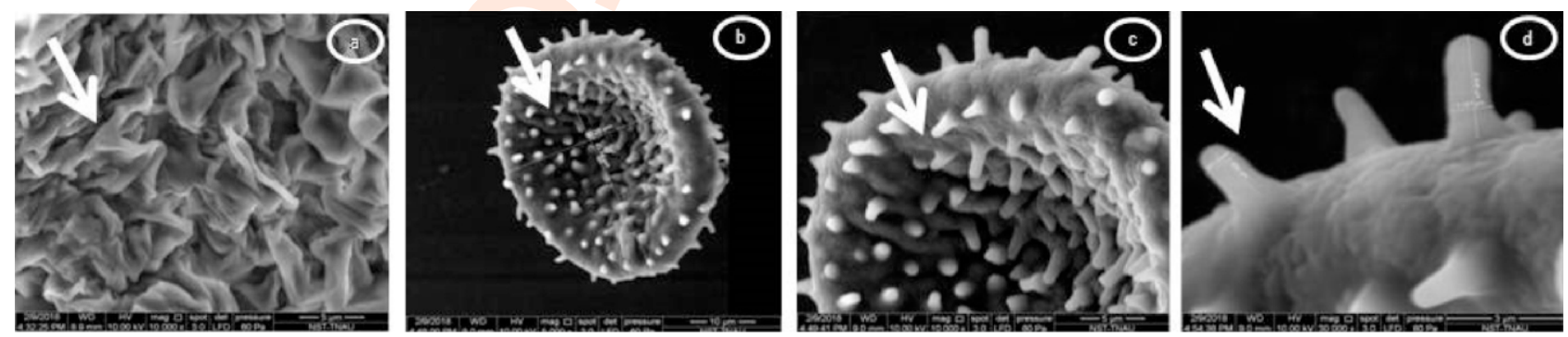

Fig. 2 (a- d) : SEM micrographs of GR:400 Gy sterile pollen of the horse gram cultivar PAIYUR 2; (a) anther wall with condensed fibre matrix ( $5 \mu M, X c$. 10000); (b) collapsed pollen (10 $\mu \mathrm{M}, \mathrm{X}$ c. 5000); (c) pollen surface with crowded pili (5 $\mathrm{M}, \mathrm{X}$ c. 10000$)$ and (d) pollen surface with reduced pili size (5 $\mu \mathrm{M}$, Xc. 30000). 

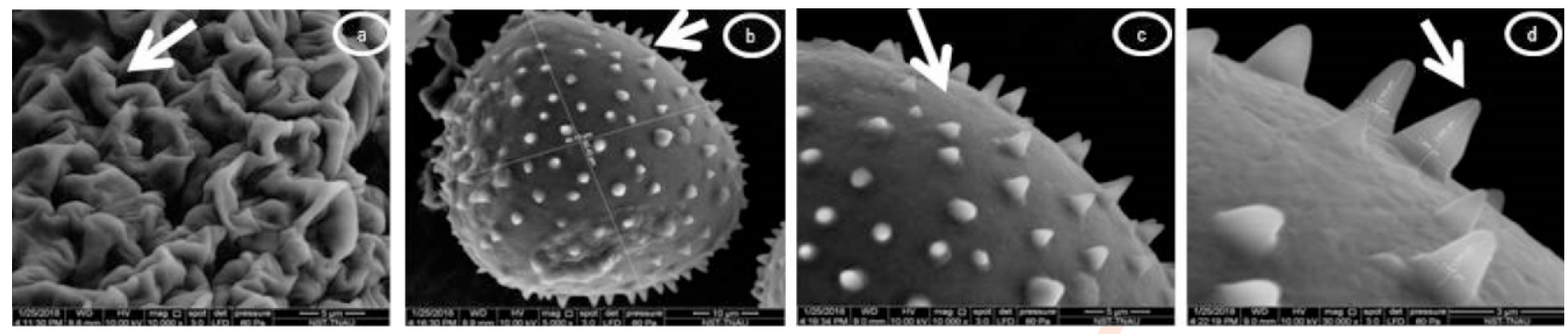

Fig. 3 (a- d) : SEM micrographs of GR:400 Gy sterile pollen of the horse gram cultivar CRIDA 1-18R; (a) Anther wall with condensed fibre matrix (5 $\mu M, X$ c. 10000); (b) Characteristic spheroidal pollen with altered size (10 $\mu \mathrm{M}, \mathrm{X}$ c. 5000); (c) Pollen surface with no brochi and absence of muri and lamina (5 $\mu \mathrm{M}, \mathrm{Xc} .10000)$ and (d) pollen surface with modified pili size ( $5 \mu \mathrm{M}, \mathrm{Xc} .30000)$.

Table 1: Changes in palynological characteristics in horse gram cultivars after higher dose of (400 Gy) gamma rays

\begin{tabular}{|c|c|c|c|c|}
\hline \multirow[t]{2}{*}{ Characteristics } & \multicolumn{2}{|c|}{ PAIYUR 2} & \multicolumn{2}{|c|}{ CRIDA 1-18R } \\
\hline & Control & G.400 Gy & Control & G - 400 Gy \\
\hline Average no. of flowers per clusters & $6.4 \pm 0.33$ & $3.10 \pm 0.46$ & $5.2 \pm 0.28$ & $2.68 \pm 0.19$ \\
\hline Pollen fertility (\%) & $93.48 \pm 0.89$ & 0.00 & $90.21 \pm 0.76$ & 0.00 \\
\hline Anther length $(\mu \mathrm{M})$ & $367.65 \pm 1.20$ & $306.85 \pm 0.98$ & $421.25 \pm 1.21$ & $279.4 \pm 0.64$ \\
\hline Anther width ( $\mu \mathrm{M})$ & $285.00 \pm 0.84$ & $340.00 \pm 1.20$ & $421.00 \pm 1.14$ & $122.0 \pm 0.91$ \\
\hline Mean pollen size in polar axis $(\mu \mathrm{M})(\mathrm{P})$ & $46.68 \pm 0.78$ & $33.28 \pm 0.61$ & $47.79 \pm 0.49$ & $46.13 \pm 0.66$ \\
\hline Mean pollen size in equatorial axis $(\mu M)(E)$ & $51.93 \pm 0.60$ & $43.54 \pm 0.88$ & $51.11 \pm 0.52$ & $53.42 \pm 0.84$ \\
\hline Index of shape (P/E) & 0.80 & 0.76 & 0.93 & 0.86 \\
\hline Pollen shape (P/E= 1 :speroidal; 0.7 to 0.97 oblate $)$ & Oblate & Oblate, collapsed & Oblate & Oblate \\
\hline Exine pattern & Reticulate & Reticulate & Reticulate & Reticulate but in patches \\
\hline Pili number per $200 \mu \mathrm{M}$ & $9.3 \pm 0.23$ & $21 \pm 0.46$ & $11.0 \pm 0.34$ & $7.25 \pm 0.18$ \\
\hline Average pili length $(\mu \mathrm{M})$ & $2.73 \pm 0.12$ & $2.38 \pm 0.14$ & $2.24 \pm 0.22$ & $2.19 \pm 0.19$ \\
\hline Average pili width $(\mu \mathrm{M})$ & $1.02 \pm 0.11$ & $1.03 \pm 0.19$ & $0.94 \pm 0.13$ & $1.46 \pm 0.12$ \\
\hline Pollen germination (\%) & $89.42 \pm 1.2$ & 0.0 & $90.26 \pm 0.9$ & 0.0 \\
\hline Seed fertility (\%) & $94.89 \pm 0.55$ & 0.00 & $90.43 \pm 0.64$ & 0.00 \\
\hline
\end{tabular}

Data are presented as mean \pm SE

rays induced altered pollen morphology, reduced pollen viability, pollen tube growth, and fertilization failure. These changes are due to GR induced abnormal microsporogenesis (Kuamr and Priyanka, 2006), variation in aperture number (Heslop - Harrison, 1971), and modification in signal receving capacity of pollen proteins (Pfahler, 1981). In this study, variation in pollen morphology led to changes in aperture number and size (Fig. 2b$\mathrm{d}$ and Table 1) which might be the reason for altered pollen function. Absence of functional pollen drastically affected seed set (Table 1).

A pronounced modification in the exine structure and ornamentation was witnessed in sterile pollens of CRIDA 1-18 R (Fig. 3b-d). In non-treated plants, the pollen sculpture was reticulate and polybrochate, but in sterile pollens only few brochi were present in a discontinuous pattern. The characteristic walls (muri) and spaces (lumina) were absent making the surface smoother compared to pollen structure in control. The deviations in exine ornamentation with reduced columellae head are indicative of abnormal tapetal function. This atypical tapetal function is fatal for reproduction perspective as normal pollen (gametophyte) development depends on a close interaction with the tapetal (sporophytic) tissue. Tapetum supplies necessary nutrients and enzymes for pollen development (Lei and Liu, 2020). Defective tapetum is linked with non-functional male meiosis, failure of meiocyte maturation (Cui et al., 2018) and reduced fertility (Chen et al., 2018). Tapetum provide precursors for exine formation (Shivanna and Johri, 1985). Tapetum layer is also involved in biosynthesis of sporopollenin (Ariizumi and Toriyama, 2011). It is speculated that a kind of tapetal changes might have reduced sporopollenin content and thereby altered the exine ornamentation. Further, increased pili width in sterile pollen is an indication of photo-synthate diversion for repair in lieu of reproductive role which was evidenced through reduced pollen fertility and seed set (Table 1). Reduced pollen fertility under irradiated condition was reported due to modified cell division and decreased mitotic index (Savaskan and Toker, 1991); resulting in 
reduced pollen tube growth (Bonhomme et al. $1998 \mathrm{a}$ and b); variation in the ability of pollen tubes in fertilization (Grini et al., 1999); and disturbance in zygote formation and embryo development (Denward, 2011). A positive correlation between pollen fertility with pollen germination and seed set was witnessed (Table 1). Similar trend was reported by Priyanka et al. (2020) and Choi et al. (2021). Further, Lasa and Bosemark (1993) opined that pollen sterility-based male sterility is the most successful, stable, and proven method in tapping the potential of heterosis in many crops including self-pollinated species. In the pollen based male sterility system the sterility is induced by abnormal microsporogenesis and therefore the chance for production of functional pollens is very rare. Therefore, a separate hybridization attempt involving gamma rays induced sterile plants (as female) and normal fertile parent (as male) was developed during the study period. It resulted in seed set (data is to be published) which indicated normal ovary function in sterile plants. Hence, from the findings of this study it can be concluded that GR:400 Gy modified the expression of morphological, flowering and phenological traits in horse gram. The changes in phonological traits resulted in male sterility without affecting the ovary function. In a plant breeding perspective, these results can be considered for development of pollen sterility based male sterility in horse gram. As the classical hybridization in horse gram involves manual emasculation and pollination. Small flower size reduces the efficiency and flower drop after pollination poses threat to the seed set percentage.

\section{Acknowledgments}

We sincerely acknowledge the Board of Research in Nuclear Sciences for providing the financial support and Dr. S. Dutta, Program Officer, Bhabha Atomic Research Centre (BARC) for timely release of grant-in-aid. The authors are immensely thankful to Dr. M. Raveendran, Professor and Head, Department of Plant Molecular Biology and Biotechnology, CPMB \& B, Tamil Nadu Agricultural University for his guidance in analyzing the experimental data and results. The authors are grateful to Dr. P. Jeyakumar, Professor and Head, Department of Crop Physiology, Crop Management Studies, TNAU for resolving the plant physiology aspects. The authors are indebted to Dr. P. Jayamani, Professor and Head, Department of Pulses, Centre for Plant Breeding and Genetics, TNAU for her relentless scientific support. The authors are beholden to the Professor and Head, and technicians of Department of Nano Science and Technology, TNAU for having spared their instrumentation facility.

\section{Add-on Information}

Author's contribution : S. Priyanka: Execution, data compilation, analysis and manuscript preparation; R. Sudhagar: Conceptualization, methodology, execution, data analysis and supervision; C. Vanniarajan: Data execution, revise, editing and fund acquistion; K. Ganesamurthy: Supervision, editing and resources; J. Souframanien: Methodology, revise, editing and fund acquisition.

Research content : The research content of manuscript is original and has not been published elsewhere.

\section{Ethical approval : Notapplicable}

Conflict of interest : The authors declare that there is no conflict of interest.

\section{Data from other sources : Not applicable}

Consent to publish : All authors agree to publish the paper in Journal of Environmental Biology.

\section{References}

Aditya, J.P., A. Bhartiya, R.K. Chahota, D. Joshi, N. Chandra, L. Kant and A. Pattanayak: Ancient orphan legume horse gram: A potential food and forage crop of future. Planta., 250, 891-909 (2019).

Ariizumi, T. and K. Toriyama: Genetic regulation of sporopollen in synthesis and pollen exine development. Annu Rev Plant Biol., 62, 437-460 (2011).

Bhardwaj, J., R. Chauhan, M.K. Swarnkar, R.K. Chahota, A.K. Singh, R. Shankar and S.K. Yadav: Comprehensive transcriptomic study on horse gram (Macrotyloma uniflorum): De novo assembly, functional characterization and comparative analysis in relation to drought stress. BMC Genomics, 14, 647 (2013).

Bhartiya, A., J.P. Aditya and L. Kant: Nutritional and remedial potential of an underutilized food legume horse gram (Macrotyloma uniflorum): Areview. J. Ani. Plant Sci., 25, 908-920 (2015).

Bolbhat, S.N., V.D. Bhoge and K.N. Dhumal: Induced mutations in horsegram (Macrotyloma uniflorum (Lam.) Verdc): Chlorophyll mutations, mutagenic efficiency and effectiveness. Int. J. Life Sci. Pharma. Res., 2, 159-168 (2012).

Bonhomme, S., C. Horlow, A. Guyon, M. Fe'rault, D. Vezon, M. Marchand, S. de Laissardière, N. Bechtold and G. Pelletier: Screening for gametophytic mutations in the Versailles collection of Arabidopsis thaliana transformants: First results for two putative male gametophytic mutants. Acta Hort., 459, 173-181 (1998a).

Bonhomme, S., C. Horlow, D. Vezon, S. De Laissardie're, A. Guyon, M. Férault, M. Marchand, N. Bechtold and G. Pelletier: T-DNA mediated disruption of essential gameto Phytic genes in Arabidopsis is unexpectedly rare and cannot be inferred from segregation distortion alone. Mol. Gen. Genet., 260, 444-452 (1998b).

Brooks, J. and G. Shaw: Sporopollenin: A review of its chemistry, palaeochemistry and geochemistry. Grana., 17, 91-97 (1978).

Chen, Z.S., X.F. Liu, D.H. Wang, R. Chen, X.L. Zhang, Z.H. Xu and S.N. Bai. Transcription factor OsTGA10 is a target of the MADS protein OsMADS8 and is required for tapetum development. Plant Physiol., 176, 819-835 (2018).

Cheng, A., S. Mayes, G. Dalle, S. Demissew and F. Massawe: Diversifying crops for food and nutrition security-a case of teff. Biol Rev., 92,188-198(2017).

Chivenge, P., T. Mabhaudhi, A.T. Modi and P. Mafongoya: The potential role of neglected and underutilised crop species as future crops under water scarce conditions in sub-saharan africa. Int. J. Environ. Res. Public Hlth., 12, 5685-5711 (2015).

Choi, H.I., S.M. Han, Y.D. Jo, M.J. Hong, S.H. Kim and J.B. Kim: Effects of acute and chronic gamma irradiation on the cell biology and physiology of rice plants. Plants, 10, 439 (2021). https://doi.org/ 10.3390/plants10030439 
CRIDA-ORP: Progress Report of Operation Research Projects of All India Coordinated Research Project on Dryland Agriculture, 519 pages (1997).

Cui, Y., C. Hu, Y. Zhu, K. Cheng, X. Li, Z. Wei, L. Xue, F. Lin, H. Shi, J. Yi, S. Hou, K. He, J. Li and X. Gou. CIK receptor kinases determine cell fate specification during early anther development in Arabidopsis. Plant Cell, 30, 2383-2401 (2018).

Denward, T:: Pollen irradiation and variability in plant breeding materials. Barley Genetics Newsletter, 41,1-9 (2011).

Desingh, R. and G. Kanagaraj: Influence of salinity stress on photosynthesis and antioxidative systems in two cotton varieties. Gen. Appl. Plant Physiol., 33, 221-234 (2007).

Duarte-Silva, E.,A. L.L.Vanzela and J.E.A. Mariath: Developmental and cytogenetic analyses of pollen sterility in Valeriana scandens $\mathrm{L}$. Sex Plant Reprod., 23,105-113 (2010).

Fuller, D.Q. and C. Murphy: The origins and early dispersal of horsegram (Macrotyloma uniforum), a major crop of ancient India. Genet Res. Crop Evol., 65, 285-305 (2018).

Gicquel, M., M.A. Esnault, J.V. Jorrin-Novo and F. Cabello-Hurtado. Application of proteomics to the assessment of the response to ionising radiation in Arabidopsis thaliana. J. Proteomics, 74, 13641377 (2011).

Grini, P.E., A. Schnittger, H. Schwarz, I. Zimmermann, B. Schwab G. Jürgens and M. Hülskamp: Isolation of ethyl methanesulfonateinduced gameto phytic mutants in Arabidopsis thaliana by a segregation distortion assay using the multimarker chromosome 1. Genetics, 151, 849-863 (1999).

Heslop-Harrison, J.: The pollen wall: structure and development. In: Pollen (Eds.: J. Heslop-Harrison), Elsevier, pp. 75-98 (1971).

Kadam, S.S., D.K. Salunkhe and J.A. Maga: Nutritional composition, processing, and utilization of horse gram and moth bean. Crit. Rev. Food Sci. Nutr., 22,1-26 (1985).

Kakani, V.G., K.R. Reddy, D. Zhao and A.R. Mohammed: Effects of ultraviolet-B radiation on cotton (Gossypium hirsutum L.) morphology and anatomy. Ann. Bot., 91, 817-826 (2003).

Kanagaraj, G. and C. Satish: Salt stress induced changes in growth, pigments and protein contents in two horse gram [Macrotyloma uniflorum (Lam.) Verdc] varieties. J. Sci. Agric., 08-18 (2017). doi:10.25081/jsa.2017.v1i0.23

Khoury, C.K., A.D. Bjorkman, H. Dempewolf, J.R. Villegas, L. Guarino, A. Jarvis, L.H. Rieseberg and C.S. Paul: Increasing homogeneity in global food supplies and the implications for food security. PNAS., 111, 4001-4006 (2014).

Koti, S., K.R. Reddy, V.G. Kakani, D. Zhao and V.R. Reddy: Soybean (Glycine max) pollen germination characteristics, flower and pollen morphology in response to enhanced ultraviolet-B radiation. Ann. Bot., 94, 855-864 (2004).

Krishna, K.R.: Agroecosystems of South India: Nutrient dynamics, ecology and productivity. Brown Walker Press, Florida, pp.372$382(2010)$

Kumar, G. and S. Dwivedi: Impact of gamma irradiation on growth response of Crotalaria juncea L. Int. J. Agric. Crop Sci., 7,870-875 (2014).

Kumar, G. and N. Srivastava: Gamma ray induced cytomorphological variations in Sesbania cannabina Poir. Cytologia, 76, 375-380 (2011).

Kumar, G. and R. Priyanka : Pleiotropic effects of y-irradiation on in-vitro pollen germination and fertility in soybean. Cytologia, 71, 315-320 (2006).

Lasa J.M. and N.O. Bosemark: Male sterility. In: Plant Breeding. Plant
Breeding Series (Eds.: M.D. Hayward., N.O. Bosemark., I. Romagosa and M. Cerezo) Springer, Dordrecht. pp.213-218 (1993). https://doi.org/10.1007/978-94-011-1524-7_15

Lei, $X$. and B. Liu: Tapetum-dependent male meiosis progression in plants: Increasing evidence emerges. Front. Plant Sci., 10, 1667 (2020).

Mabhaudhi, T., V.G.P. Chimonyo, T.P. Chibarabada and A.T. Modi: Developing a roadmap for improving neglected and underutilized crops: A case study of South Africa. Front Plant Sci., 8, 2143 (2017).

Mackenzie, G., S. Beckett, S. Atkin and A. Diego-Taboada: Pollen and spore shells-nature's microcapsules. In: Microencapsulation in the Food Industry (Eds.: A.G. Gaonkar, N. Vasisht, A.R. Khare and R. Sobel) pp. 283-297 (2014).

Mahajan, V., S.K. Shukla, N.S. Gupta, D. Majumdera, V. Tiwari and S.V.S. Prasad: Identifying phenotypically stable genotypes and developing strategy for yield improvement in horse gram (Macrotyloma uniflorum) for mid altitudes of North-western Himalayas. Ind. J. Agric. Sci., 3, 19-22 (2007).

Nurmansyah, S.S. Alghamdi, H.M. Migdadi and M. Farooq: Morphological and chromosomal abnormalities in gamma radiation-induced mutagenized faba bean genotypes. Int. J. Radiat. Biol., 94,174-185(2017).

Parida, A.K. and B. Das: Salt tolerance and salinity effects on plants. Ecotoxicol. Environ. Saf., 60, 324-349 (2005).

Pfahler, P. L.: In vitro germination of maize to detect biological activity of environmental pollutants. Environ. Hlth. Perspect., 37, 125-132 (1981).

Prasad, S.K. and M.K. Singh: Horse gram-An underutilized nutraceutical pulse crop: a review. J. Food Sci. Technol., 52, 2489-2499 (2015).

Priyanka, S., R. Sudhagar., C. Vanniarajan., K. Ganesamurthy and J. Souframanien: Combined mutagenic ability of gamma ray and EMS in horse gram (Macrotyloma uniflorum (Lam) Verdc.). Electron. J. Plant Breed., 10, 1086-1094 (2019).

Priyanka, S., R. Sudhagar, C. Vanniarajan, K. Ganesamurthy, J. Souframanien and P. Jeyakumar: Comparative studies on mutagenic effectiveness and efficiency in horse gram [Macrotyloma uniflorum (Lam) Verdc.]. Legume Res., (2020). (online first) 10.18805/LR-4408

Rick, C.M.: The genetic nature of X-ray induced changes in pollen. Proc. Nat. Acad. Sci., 28, 518-525 (1942)

Sari-Gorla, M., S. Ferrario, M. Villa and M.E. Pe: gaMS-1, a gametophytic expressed male sterile mutant of maize. Sex. Plant Reprod., 9 , 215-220 (1996).

Savaskan, Ç. and M.C. Toker: The effects of various doses of gamma irradiation on the seed germination and root tips chromosomes of rye (Secale cereale L.). Tr.J. Bot., 15, 349-359 (1991).

Savaskan, Ç.: The effects of gamma irradiation on the pollen size of Gossypium hirsutum L. Tr. J. Bot., 26, 477-480 (2002).

Sharma, V., M. Rana, M. Katoch, P.K. Sharma, M. Ghani, J.C. Rana, T.R. Sharma and R.K. Chahota: Development of SSR and ILP markers in horsegram (Macrotyloma uniflorum), their characterization, cross-transferability and relevance for mapping. Mol. Breed., $35,102(2015)$.

Shivanna, K.R. and B.M. Johri: The Angiosperm Pollen. Structure and function. Wiley Eastern Ltd., New Delhi (1985).

Singh, A.K. and R.M. Singh: Mutagenic effectiveness and efficiency of gamma rays, ethyl methane sulphonate and their combination in mungbean. Crop Improv., 28, 260-266 (2001). 